The Canadian Mineralogist

Vol. 43, pp. 1043-1053 (2005)

\title{
STRUCTURE AND CATION ORDER IN MANGANILVAITE: A COMBINED X-RAY-DIFFRACTION, NEUTRON-DIFFRACTION AND MÖSSBAUER STUDY
}

\author{
NIKOLAY ZOTOV ${ }^{\S}$ AND WINFRIED KOCKELMANN \\ Mineralogisch-Petrologisches Institut, Universität Bonn, Poppelsdorfer Schloss, D-53115 Bonn, Germany
}

STEVEN D. JACOBSEN

Geophysical Laboratory, Carnegie Institution of Washington, Washington, D.C. 20015, USA

IVAN MITOV AND DANIELA PANEVA

Institute of Catalysis, Bulgarian Academy of Sciences, 1113 Sofia, Bulgaria

RosSITSA D. VASSILEVA AND IVAN K. BONEV

Geological Institute, Bulgarian Academy of Sciences, 1113 Sofia, Bulgaria

\section{ABSTRACT}

The crystal structure of manganilvaite, $\mathrm{CaFe}^{2+} \mathrm{Fe}^{3+}\left(\mathrm{Mn}^{2+}, \mathrm{Fe}^{2+}\right)\left(\mathrm{Si}_{2} \mathrm{O}_{7}\right) \mathrm{O}(\mathrm{OH})$, from the Ossikovo $\mathrm{Pb}-\mathrm{Zn}$ skarn deposit, Rhodope Mountains, Bulgaria, was refined in space group $P 2_{1} / a$, with $a 13.0250(7), b 8.8514(5), c 5.8486(3) \AA ̊ ., \beta 90.167(1)^{\circ}$, $V 674.28(7) \AA^{3}, Z=4$, using combined neutron and X-ray powder diffraction as well as single-crystal X-ray-diffraction data. The empirical chemical formula proposed on the basis of the Rietveld refinements is: $\left(\mathrm{Ca}_{0.9} \mathrm{Mn}^{2+}{ }_{0.1}\right)\left(\mathrm{Fe}^{2+}{ }_{0.83} \mathrm{Fe}^{3+}{ }_{0.17}\right)\left(\mathrm{Fe}^{2+}{ }_{0.17}\right.$ $\left.\mathrm{Fe}^{3+}{ }_{0.83}\right)\left(\mathrm{Mn}^{2+}{ }_{0.51} \mathrm{Fe}^{2+}{ }_{0.49}\right)\left(\mathrm{Si}_{2} \mathrm{O}_{7}\right) \mathrm{O}(\mathrm{OH})$. The occupancy of the $M 11$ site $\left(0.83 \mathrm{Fe}^{2+}+0.17 \mathrm{Fe}^{3+}\right)$ corresponds to an order parameter $\mathrm{Q}$ of $0.65(10)$. The high $\mathrm{Mn}$ content leads to strong enhancement (14\%) of $\mathrm{Fe}^{2+} \rightarrow \mathrm{Fe}^{3+}$ charge transfer in comparison to Mn-free ilvaite from Seriphos, Greece, as observed by Mössbauer spectroscopy.

Keywords: manganilvaite, combined X-ray and neutron powder diffraction, single-crystal X-ray diffraction, Mössbauer spectroscopy, Rietveld refinement, Ossikovo mine, Bulgaria.

\section{SOMMAIRE}

Nous avons affiné la structure cristalline de la manganilvaïte, $\mathrm{CaFe}^{2+} \mathrm{Fe}^{3+}\left(\mathrm{Mn}^{2+}, \mathrm{Fe}^{2+}\right)\left(\mathrm{Si}_{2} \mathrm{O}_{7}\right) \mathrm{O}(\mathrm{OH})$, provenant du gisement à $\mathrm{Pb}-\mathrm{Zn}$ de type skarn de Ossikovo, dans les montagnes Rhodope, en Bulgarie, dans le groupe spatial $P 2_{1} / a$, avec $a$ 13.0250(7), $b$ 8.8514(5), c 5.8486(3) $\AA, \beta$ 90.167(1) ${ }^{\circ}, V$ 674.28(7) $\AA^{3}, Z=4$, en utilisant des données obtenues par diffraction $X$ et neutronique sur poudre ainsi que par diffraction $\mathrm{X}$ sur monocristal. La formule chimique empirique proposée selon les résultats obtenus d'affinements de Rietveld est: $\left(\mathrm{Ca}_{0.9} \mathrm{Mn}^{2+}{ }_{0.1}\right)\left(\mathrm{Fe}^{2+}{ }_{0.83} \mathrm{Fe}^{3+}{ }_{0.17}\right)\left(\mathrm{Fe}^{2+}{ }_{0.17} \mathrm{Fe}^{3+}{ }_{0.83}\right)\left(\mathrm{Mn}^{2+}{ }_{0.51} \mathrm{Fe}^{2+}{ }_{0.49}\right)\left(\mathrm{Si}_{2} \mathrm{O}_{7}\right) \mathrm{O}(\mathrm{OH})$. Le site $M 11$ contient $\left(0.83 \mathrm{Fe}^{2+}+0.17 \mathrm{Fe}^{3+}\right)$, ce qui correspond à un paramètre d'ordre $\mathrm{Q}$ de $0.65(10)$. La teneur élevée en Mn mène à un tranfert accru des charges de $\mathrm{Fe}^{2+}$ à $\mathrm{Fe}^{3+}(14 \%)$, en comparaison du cas de l'ilvaïte dépourvue de Mn provenant de Seriphos, en Grèce, selon la spectroscopie de Mössbauer.

(Traduit par la Rédaction)

Mots-clés: manganilvaïte, combinaison de diffraction $\mathrm{X}$ et neutronique sur poudre, diffraction $\mathrm{X}$ sur monocristal, spectroscopie de Mössbauer, affinement de Rietveld, mine Ossikovo, Bulgarie.

\& E-mail address: nzotov@uni-bonn.de 


\section{INTRODUCTION}

Ilvaite is a mixed-valence iron-dominant sorosilicate, $\mathrm{CaFe}^{2+}{ }_{2} \mathrm{Fe}^{3+}\left(\mathrm{Si}_{2} \mathrm{O}_{7}\right) \mathrm{O}(\mathrm{OH})$, common in $\mathrm{Fe}$, $\mathrm{Cu}$, and $\mathrm{Pb}-\mathrm{Zn}$ skarn-type ore deposits. Manganilvaite, $\mathrm{CaFe}^{2+} \mathrm{Fe}^{3+}\left(\mathrm{Mn}^{2+}, \mathrm{Fe}^{2+}\right)\left(\mathrm{Si}_{2} \mathrm{O}_{7}\right) \mathrm{O}(\mathrm{OH})$, from the Rhodope Mountains, Bulgaria was described by Bonev et al. (2005) as a new mineral species, the manganesedominant member of the ilvaite group of minerals. Here, we provide crystal-chemical characterization of this mineral with high Mn content and resolve the problem concerning the distribution of Mn using combined neutron and X-ray refinements, as well as Mössbauer spectroscopy. Neutron diffraction is particularly suited for this problem because $\mathrm{Mn}$ has a negative neutronscattering length $\left(b_{M n}=-3.73 \mathrm{fm}\right)$ and can be readily distinguished from $\mathrm{Fe}$, in contrast with X-ray-diffraction techniques.

\section{PREVIOUS WORK}

The crystal structure of orthorhombic ilvaite was first determined by Belov \& Mokeeva (1954) (space group Pbnm) and re-investigated by Beran \& Bittner (1974) and Haga \& Takéuchi (1976). Bartholomé et al. (1968) established the existence of a monoclinic ilvaite-type phase in space group $P 2_{1} / a$, with only small deviation from the orthorhombic Pnam symmetry (in the space group Pnam, the $a$ and $b$ axes are interchanged compared to Pbnm, and $a>b>c$ ). The monoclinic structure was later refined by Finger et al. (1982), Takéuchi et al. (1983, 1993, 1994), Ghose et al. (1984, 1985, 1989), Finger \& Hazen (1987), Carrozzini (1994), and Bonazzi \& Bindi (1999). Crystal-chemical relationships between the cation-order parameter Q and the angle $\beta$ (Finger \& Hazen 1987, Carrozzini 1994), as well as effects of heat treatment on Q, have been reported (Bonazzi \& Bindi 1999). The structure of orthorhombic ilvaite consists of double chains of edge-sharing Fe octahedra ( $M 1$ site) running along the $c$ axis and cross-linked by additional Fe octahedra (M2 site), ${ }^{[7]} \mathrm{Ca}$ polyhedra and $\left[\mathrm{Si}_{2} \mathrm{O}_{7}\right]$ sorosilicate groups. In the structure of monoclinic ilvaite, the $M 1$ site splits into two sites, $M 11$ and $M 12$ (Fig. 1). Divalent Mn is the most common and quantitatively relevant impurity in natural ilvaite, substituting mainly for $\mathrm{Fe}^{2+}$ and, to a lesser extent, $\mathrm{Ca}^{2+}$ (Cocco \& Garavelli 1954). The $\mathrm{Mn}$ content of natural ilvaite is usually below $\sim 2 \mathrm{wt} . \%$ $\mathrm{MnO}$, but higher contents, up to 14.96 wt. $\% \mathrm{MnO}$, have been reported (Bonev et al. 2005). The pattern of order of $\mathrm{Mn}^{2+}$ among the $M 11, M 12$ and $M 2$ octahedral sites is still somehow contradictory. In ilvaite, $\mathrm{Mn}^{2+}$ substitutes for $\mathrm{Fe}^{2+}$ predominantly at the $M 2$ site (Haga \& Takéuchi 1976, Carrozzini 1994, Bonazzi \& Bindi 2002), although more disordered distributions of $\mathrm{Mn}$ were reported by Takéuchi et al. (1993) for crystals from Tochibara (Japan) and by Carrozzini (1994) for crystals from Oridda, Sardinia (Italy), whereas synthetic Mn-doped ilvaite exhibits very different distributions of cations (Ghazi-Bayat et al. 1989, Cesena et al. 1995). The temperature of the monoclinic-orthorhombic phase transition depends also on the $\mathrm{Mn}^{2+}$ content (Ghose et al. 1984, 1989, Finger \& Hazen 1987, Ghazi-Bayat et al. 1989, 1992, Amthauer et al. 1998).

\section{Material}

The description of manganilvaite and of its occurrence is given by Bonev et al. (2005). The material used for structural studies was selected from the bulk sample Os-8 (Bonev et al. 2005); it is rather enriched in the mineral, making it possible to pick out the large quantities necessary for powder neutron and X-ray diffraction. Electron-microprobe analysis of mm-sized single crystals showed variations in the Mn content, from 9.02 up to $12.58 \mathrm{wt}$ \% $\mathrm{MnO}$. However, the variations are gradual and are not visible either in back-scattered images or in thin doubly polished sections under the infrared microscope. The mean composition, as determined from 26 electron-microprobe analyses, is (in wt.\%): $\mathrm{CaO} 12.57, \mathrm{MnO} 10.79, \mathrm{MgO} 0.44, \mathrm{Al}_{2} \mathrm{O}_{3}$ $0.31, \mathrm{FeO}_{\text {tot }} 41.06$, sum 94.74. The amount of $\mathrm{H}_{2} \mathrm{O}$ (2.20 wt.\%) was measured separately by heating. The ICP analysis of this material gave MnO 10.52 wt.\%. However, other specimens from the same locality exhibit higher Mn contents (reaching nearly 15 wt.\% $\mathrm{MnO}$; see Bonev et al. 2005), although such material present as disseminated small grains.

A nearly stoichiometric Mn-free ilvaite from the Seriphos ilvaite deposit, in the Cyclade Isles, Greece, also was studied by X-ray and neutron powder-diffraction as well as by Mössbauer spectroscopy. We established its chemical homogeneity by electron-microprobe analysis; it contains only a low content of $\mathrm{Mg}(0.1 \mathrm{wt} . \%$ $\mathrm{MgO}$, see Table 5 of Bonev et al. 2005).

\section{EXPERIMENTAL}

The X-ray powder-diffraction measurements were done in transmission geometry with a PSD detector in the range $12^{\circ} \leq 2 \theta \leq 120^{\circ}$, step size of $2 \theta 0.02^{\circ}$ and 10 $\mathrm{s}$ per step at room temperature on a Stoe X-ray powder diffractometer equipped with $\mathrm{Ge}$ monochromator using $\mathrm{CoK} \alpha_{1}$ radiation $(\lambda=1.78897 \AA)$, operating at $40 \mathrm{kV}$ and $30 \mathrm{~mA}$. The neutron-diffraction measurements were done on the time-of-flight ROTAX diffractometer at the ISIS spallation source, Rutherford Appleton Laboratory (UK). The ROTAX instrument is equipped with three banks of detectors at average $2 \theta$ positions $28.8^{\circ}$ (bank A), $72.8^{\circ}$ (bank B) and $122.3^{\circ}$ (bank C). The powdered samples were loaded into vanadium cans $8 \mathrm{~mm}$ in diameter. Both the manganilvaite and the Seriphos ilvaite were measured at room temperature for about $12 \mathrm{~h}$, and the intensities were normalized against a vanadium stan- 
dard. The back-scattering bank $\mathrm{C}$ allowed us to collect data with good statistics for a wider momentum-transfer range than is normally the case with $\mathrm{X}$ rays.

Combined refinement of the X-ray and three neutron powder-diffraction datasets was done using GSAS (Larson \& Von Dreele 1987). The X-ray peak profiles were fitted with the Thompson-Cox pseudo-Voigt function, whereas the neutron peak profiles were fitted with double-exponential pseudo-Voigt convolution function (Larson \& Von Dreele 1987). The profile parameters for each histogram were refined in the initial stages of the refinements, and then fixed. During the final cycles of least-squares refinement, the scale factors, the background coefficients (fifth-order polynomials) and the zero shifts for all histograms, lattice parameters, positional parameters, occupancy factors and isotropicdisplacement factors were refined. The isotropicdisplacement parameters of each of the $\mathrm{Fe}, \mathrm{Si}$ and $\mathrm{O}$ atoms were kept equal during refinements.

A single-crystal X-ray-diffraction study of manganilvaite was done using a Bruker $P 4$ rotatinganode four-circle diffractometer operating at $50 \mathrm{kV}$ and $250 \mathrm{~mA}$, with an $18 \mathrm{~kW}$ generator. The high-intensity source was monochromated by a vertical incident-beam graphite monochromator. The wavelength is calibrated against an IUCr ruby standard before and after cellparameter measurements. The cell parameters of three different crystals of manganilvaite from the Ossikovo mine were determined by least-squares fitting the centered positions of 20 or 30 low-angle reflections $\left(2 \theta<30^{\circ}\right)$, and show some variability at the $5 \sigma$ level due to variability in composition. The crystal showing the sharpest diffraction-peak profiles and measuring about $60 \times 80 \times 120 \mathrm{~mm}$ was selected for intensity data collection using variable-speed $\theta-2 \theta$ scans (from 4 to $10^{\circ}$ per minute) on the twice-redundant hemisphere $(h+20, k \pm 14, l \pm 9)$ out to $2 \theta_{\max }=70^{\circ}$, resulting in 6333 reflections in total, with 2673 considered unique and having $\mathrm{I}>2 \sigma(\mathrm{I})$. The data were correcting for Lorentz, polarization and absorption effects. An analytical absorption correction was applied using the indexed faces and measured distances of the crystal,

\begin{tabular}{|c|c|c|c|c|}
\hline & \multicolumn{2}{|c|}{ Ilvaite, Seriphos } & \multicolumn{2}{|c|}{ Manganilvaite, Ossikovo } \\
\hline & $\begin{array}{l}\text { Powder } \\
\text { neutrons }\end{array}$ & $\begin{array}{c}\text { Powder } \\
\mathrm{x} \text {-ray }+ \text { neutrons }\end{array}$ & $\begin{array}{c}\text { Powder } \\
\text { X-ray + neutrons }\end{array}$ & $\begin{array}{c}\text { Single-crystal } \\
X \text {-ray }\end{array}$ \\
\hline$a, \AA$ & $13.0207(7)$ & $13.0146(3)$ & $13.0250(7)$ & $13.015(2)$ \\
\hline$b$ & $8.8121(4)$ & $8.8046(2)$ & $8.8514(5)$ & $8.8430(8)$ \\
\hline$c$ & $5.8609(3)$ & $5.8588(2)$ & $5.8486(3)$ & $5.8396(5)$ \\
\hline$\beta^{\circ}$ & $90.25(1)$ & $90.28(1)$ & $90.167(1)$ & $90.11(1)$ \\
\hline$V, A^{3}$ & $672.48(8)$ & $671.34(3)$ & $674.28(7)$ & $672.12(10)$ \\
\hline$R_{w p} \%$ & 14.7 & 2.4 & 2.1 & $3.4\left(R_{w} 3.5\right)$ \\
\hline
\end{tabular}

$\$$ Ghose et al. (1984). The space group, in each case: $P 2_{1} / a$. after which the data merging of equivalent reflections gave a discrepancy factor $R_{\text {int }}=0.081$. The structure was refined from the starting positions reported by Finger \& Hazen (1987) using SHELX-97 (Sheldrick 1997) and $\mathrm{w}=1.0 /\left(\sigma^{2}(\mathrm{~F})+0.000030 \mathrm{~F}^{2}\right)$ weighting scheme and converged to $R_{w}=3.4 \%$.

The Mössbauer spectroscopy was done on an electromechanical Wissel (Wissenschaftliche Elektronik $\mathrm{GmBH})$ spectrometer at room temperature. $\mathrm{A}^{57} \mathrm{Co} / \mathrm{Cr}$ source with an activity $10 \mathrm{mCi}$ was used with $\alpha$-Fe as a standard. The experimental spectra were fitted as a sum of Lorentzians using the least-squares method.

\section{RESULTS}

\section{Diffraction studies}

The lattice parameters of the Seriphos ilvaite (Table 1) are in close agreement with the powder neutron-diffraction results of Ghose et al. (1984) and with the single-crystal X-ray data of Carrozzini (1994). In agreement with previous studies (Carrozzini 1994, Bonazzi \& Bindi 2002), increasing Mn content correlates with an increase in the $b$ parameter (Fig. 2), whereas $a$ and $c$ remain practically unchanged.

Several models for the Mn occupancy in manganilvaite were examined using combined neutron and X-ray powder refinements (Finney 1995). Simultaneous refinement of the $\mathrm{Mn}$ occupancies at the $M 11, M 12$ and $M 2$ sites failed, indicating that Mn occurs only at the $M 2$ site. The structure was refined with Mn only at the $M 2$ site, and the refinement converged to $R_{w p}=2.3 \%$. Mn was then allowed to substitute for $\mathrm{Ca}$ at the seven-coordinated site. The residual $R_{w p}$ converged to $2.1 \%$, with $R_{w p}=4.8 \%$ for X-ray and $R_{w p}$ of $2.3,2.4$ and $1.7 \%$ for neutron banks A, B and C, respectively. In the Mn-free ilvaite from Seriphos, the refinement converged to an overall $R_{w p}$ of $2.4 \%$. The X-ray-diffraction pattern for manganilvaite is shown together with the fitted intensities in Figure 3a. The low- $2 \theta$ neutron-diffraction pattern (bank A), which is the most sensitive to the occupancy factors, together with the fitted intensities, is shown in Figure $3 b$.

Atom parameters are listed in Table 2. The coordinates for the structural model derived from the combined neutron + X-ray powder-diffraction data are in good agreement with the single-crystal data. The refined occupancies for manganilvaite and for the Seriphos ilvaite are given in Table 3.

The $\langle M 11-\mathrm{O}\rangle$ distance in manganilvaite is very similar to that in the Seriphos ilvaite (Table 4) and other samples of Mn-poor ilvaite (Takéuchi et al. 1983, Finger \& Hazen 1987, Carrozzini 1994, Bonazzi \& Bindi 1999), which supports the premise that $\mathrm{Mn}^{2+}$ does not occur at the M11 site, despite the very large total $\mathrm{Mn}$ content. The substitution of $\mathrm{Mn}^{2+}$ for $\mathrm{Fe}^{2+}$ at $M 2$ increases $\langle M 2-\mathrm{O}\rangle$, reflecting the greater ionic radius of $\mathrm{Mn}^{2+}$ (0.830 versus $0.780 \AA$, respectively: Shannon 

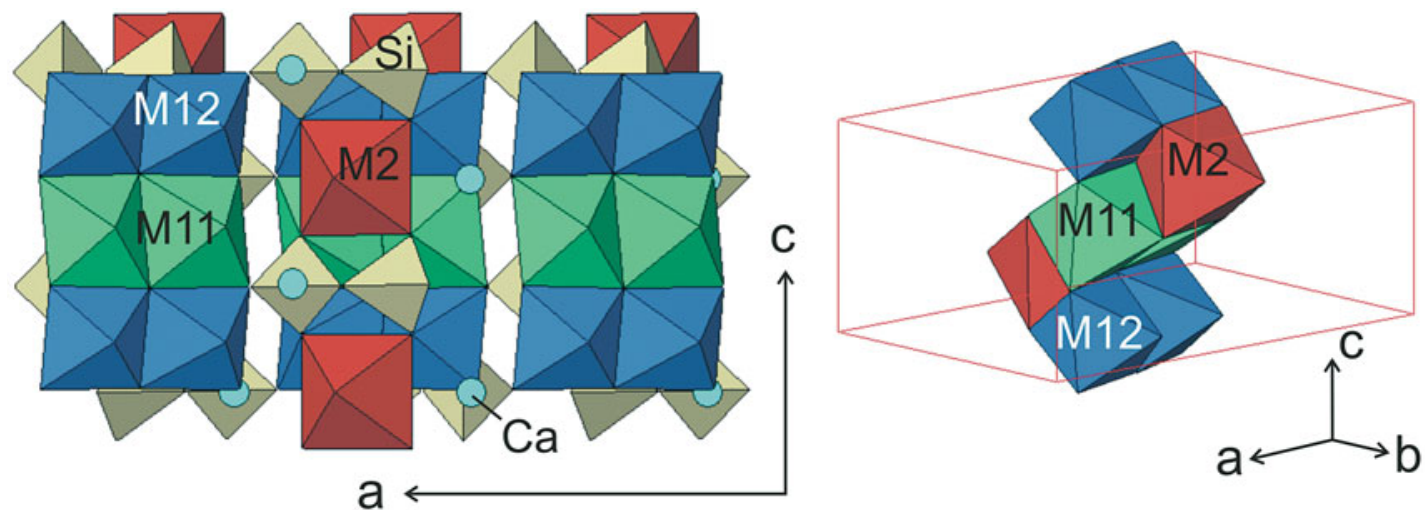

FIG. 1. The crystal structure of manganilvaite and view of one of the double chains of edge-sharing octahedra $M 11-M 12$ and $M 2$.

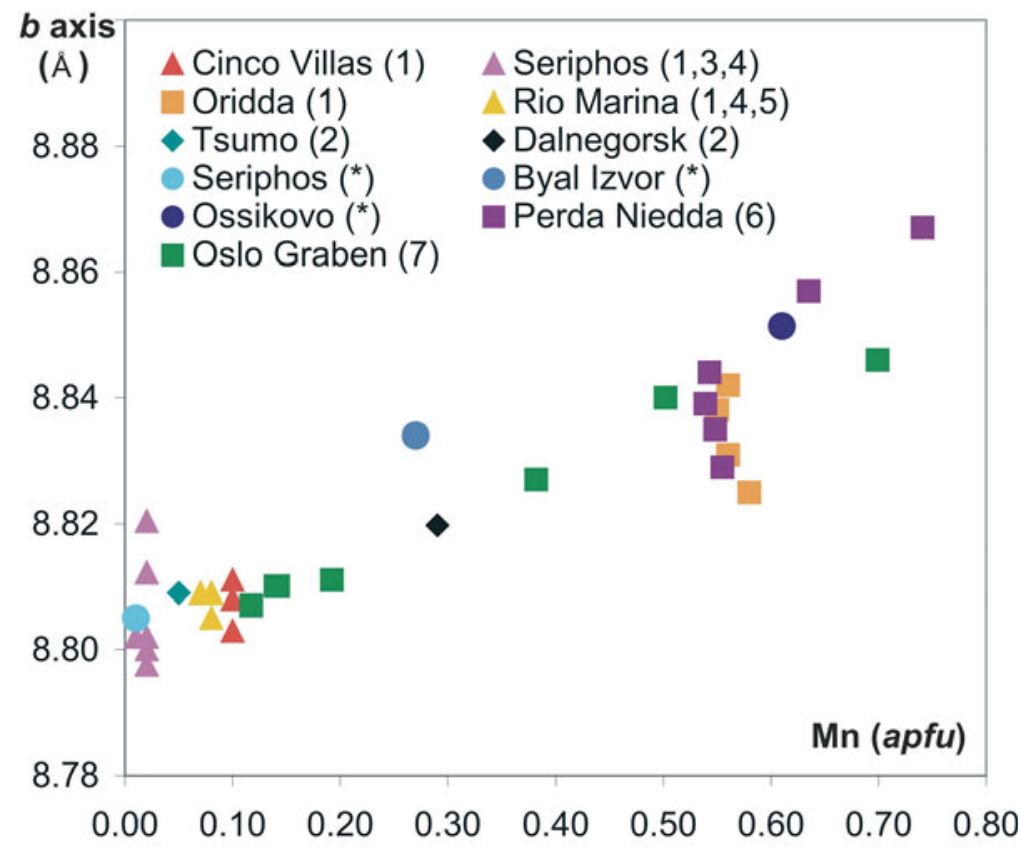

FIG. 2. Variation of $b$ versus $\mathrm{Mn}$ content (in $a p f u$ ) in ilvaite-manganilvaite. Data from: (1) Carrozzini (1994), (2) Takéuchi et al. (1983), (3) Finger \& Hazen (1987), (4) Ghose et al. (1984), (5) Bonazzi \& Bindi (1999), (6) Bonazzi \& Bindi (2002), (7) Larsen \& Dahlgren (2002), and the present study (*).

1976). The $<M 2-\mathrm{O}>$ bond length is a linear function of Mn content (Fig. 4), in accord with correlation proposed by Carrozzini (1994) and Bonazzi \& Bindi (2002). Also, $\langle M 2-\mathrm{O}\rangle_{\text {obs }}$ equals 2.201(1) A (Table $4)$, whereas $\langle M 2-\mathrm{O}\rangle_{\text {calc }}$ equals $2.200(1) \AA$ using the empirical equation $\langle M 2-\mathrm{O}\rangle=2.1869(3)+0.0266(9)$
$n\left(\mathrm{Mn}^{2+}\right)$, reported by Bonazzi \& Bindi (2002), where $n\left(\mathrm{Mn}^{2+}\right)$ is the Mn occupancy at the $M 2$ site. The $M 11$, $M 12$ and $M 2$ octahedra in the ilvaite structure are not regular. In the Seriphos $\mathrm{Mn}$-free ilvaite, the $M 2$ site has the largest bond-length $\langle\Delta \mathrm{l}\rangle$ and bond-angle $\langle\Delta \tau\rangle$ distortions among the octahedra (Table 5). 
TABLE 2. ATOM COORDINATES AND ISOTROPIC DISPLACEMENT PARAMETERS FOR MANGANILVAITE

\begin{tabular}{|c|c|c|c|c|c|c|c|c|}
\hline & \multicolumn{4}{|c|}{ Powder X-ray + neutrons } & \multicolumn{4}{|c|}{ Single-crystal X-ray } \\
\hline & $x$ & $y$ & $z$ & $U e^{\star} 100$ & $x$ & $y$ & $z$ & $U e^{* 100}$ \\
\hline $\mathrm{Ca}$ & $0.8150(3)$ & $0.3729(3)$ & $0.7630(1)$ & $0.54(9)$ & $0.81298(3)$ & $0.36996(5)$ & $0.75154(8)$ & $0.75(1)$ \\
\hline M11 & $0.8912(3)$ & $0.0504(5)$ & $0.0072(4)$ & $0.49(2)$ & $0.89021(2)$ & $0.04995(4)$ & $0.00689(6)$ & $0.734(8)$ \\
\hline$M 12$ & $0.8886(2)$ & $0.0501(5)$ & $0.4953(5)$ & $0.49(2)$ & $0.89018(2)$ & $0.05095(4)$ & $0.49337(6)$ & $0.704(8)$ \\
\hline$M 2$ & $0.9421(3)$ & $0.7395(5)$ & $0.2561(2)$ & $0.49(2)$ & $0.93987(3)$ & $0.73906(4)$ & $0.24925(6)$ & $0.738(8)$ \\
\hline Si1 & $0.9587(2)$ & $0.3693(3)$ & $0.2599(1)$ & $0.37(4)$ & $0.95890(5)$ & $0.36741(7)$ & $0.2495(1)$ & $0.50(1)$ \\
\hline $\mathrm{Si} 2$ & $0.6820(3)$ & $0.2262(3)$ & $0.2439(2)$ & $0.37(4)$ & $0.67971(5)$ & $0.22663(7)$ & $0.2511(1)$ & $0.52(1)$ \\
\hline 01 & $0.0100(2)$ & $0.0270(3)$ & $0.7378(7)$ & $0.027(7)$ & $0.0092(1)$ & $0.0264(2)$ & $0.7443(3)$ & $1.02(4)$ \\
\hline $\mathrm{O} 21$ & $0.9376(3)$ & $0.2731(6)$ & $0.0140(7)$ & $0.027(7)$ & $0.9366(1)$ & $0.2717(2)$ & $0.0158(3)$ & $0.78(4)$ \\
\hline $\mathrm{O} 22$ & $0.9340(3)$ & $0.2722(6)$ & $0.4799(7)$ & $0.027(7)$ & $0.9361(1)$ & $0.2716(2)$ & $0.4844(3)$ & $0.79(4)$ \\
\hline $\mathrm{O} 3$ & $0.7764(2)$ & $0.1071(2)$ & $0.2598(7)$ & $0.027(7)$ & $0.7767(1)$ & $0.1081(2)$ & $0.2526(3)$ & $0.77(4)$ \\
\hline O41 & $0.6762(3)$ & $0.3330(5)$ & $0.0208(6)$ & $0.027(7)$ & $0.6715(1)$ & $0.3282(2)$ & $0.0185(3)$ & $0.79(4)$ \\
\hline $\mathrm{O} 42$ & $0.6678(3)$ & $0.3258(5)$ & $0.4842(6)$ & $0.027(7)$ & $0.6713(1)$ & $0.3303(2)$ & $0.4821(3)$ & $0.74(4)$ \\
\hline O5 & $0.5836(2)$ & $0.1018(2)$ & $0.2616(7)$ & $0.027(7)$ & $0.5845(1)$ & $0.1018(2)$ & $0.2515(3)$ & $0.68(4)$ \\
\hline O6 & $0.6028(2)$ & $0.0215(2)$ & $0.7605(7)$ & $0.027(7)$ & $0.6033(1)$ & $0.0224(2)$ & $0.7513(3)$ & $1.07(4)$ \\
\hline 07 & $0.7973(2)$ & $0.1120(2)$ & $0.7422(8)$ & $0.027(7)$ & $0.7978(1)$ & $0.1103(2)$ & $0.7474(3)$ & $0.76(4)$ \\
\hline $\mathrm{H}$ & $0.7285(3)$ & $0.0644(4)$ & $0.7549(2)$ & $2.05(10)$ & $0.733(4)$ & $0.094(7)$ & $0.743(11\rangle$ & $0.6(2)$ \\
\hline
\end{tabular}

\begin{tabular}{|c|c|c|}
\hline lethod & Ca site & M2 site \\
\hline \multicolumn{3}{|c|}{ Manganilvaite, Ossikovo } \\
\hline $\begin{array}{l}\text { owder X-ray } \\
\text { neutrons }\end{array}$ & $0.903(3) \mathrm{Ca}+0.097(3) \mathrm{Mn}$ & $0.503(2) \mathrm{Mn}+0.497(2) \mathrm{Fe}$ \\
\hline $\begin{array}{l}\text { ngle-crystal } \\
\text {-ray }\end{array}$ & $1 \mathrm{Ca}$ & $0.56(4) \mathrm{Mn}+0.44(4) \mathrm{Fe}$ \\
\hline \multicolumn{3}{|c|}{$\left(\mathrm{Ca}_{0.9} \mathrm{Mn}^{2+}{ }_{0.1}\right)\left(\mathrm{Fe}_{0.83}^{2+} \mathrm{Fe}_{0.17}^{3+}\right)\left(\mathrm{Fe}_{0.17}^{2+} \mathrm{Fe}_{0.83}^{3+}\right)\left(\mathrm{Mn}_{0.51}^{2+} \mathrm{Fe}_{0.49}^{2+}\right)\left(\mathrm{Si}_{2} \mathrm{O},\right) \mathrm{O}(\mathrm{OH})$} \\
\hline \multicolumn{3}{|c|}{ Ilvaite, Seriphos } \\
\hline $\begin{array}{l}\text { owder X-ray } \\
\text { neutrons }\end{array}$ & $1 \mathrm{Ca}$ & $0.01(1) \mathrm{Mn}+0.99(1) \mathrm{Fe}$ \\
\hline
\end{tabular}

Both $\mathrm{Fe}^{2+}$ and $\mathrm{Fe}^{3+}$ occupy the $M 11$ and the $M 12$ sites. An order parameter Q has been proposed (Takéuchi et al. 1983, Ghose et al. 1984, Finger \& Hazen 1987), depending on the $\mathrm{Fe}^{3+}$ occupancy $\left[n\left(\mathrm{Fe}^{3+}\right)\right]$ of the $M 11$ site: $\mathrm{Q}=\left|0.5-n\left(\mathrm{Fe}^{3+}\right)\right| / 0.5$; $\mathrm{Q}$ equals 1 for complete order, with $\mathrm{Fe}^{2+}$ and $\mathrm{Fe}^{3+}$ at the $M 11$ and $M 12$ sites, respectively (monoclinic symmetry), whereas $\mathrm{Q}$ is 0 for complete disorder (orthorhombic symmetry). The $\mathrm{Fe}^{3+}$ occupancy of $M 11$ can be expressed as a function of $\langle M 11-\mathrm{O}\rangle$ assuming $\left\langle\mathrm{Fe}^{2+}-\mathrm{O}\right\rangle=2.135 \AA$ and $\left.<\mathrm{Fe}^{3+}-\mathrm{O}\right\rangle=2.025 \AA$ (Ghose et al. 1984): $n\left(\mathrm{Fe}^{3+}\right)=$ $\left.\left.\left[<\mathrm{Fe}^{2+}-\mathrm{O}>-<M 11-\mathrm{O}\right\rangle\right] /\left[<\mathrm{Fe}^{2+}-\mathrm{O}>-<\mathrm{Fe}^{3+}-\mathrm{O}\right\rangle\right]$.

In the Seriphos ilvaite, $\mathrm{Q}$ equals $0.73(10)$. Hence, $\mathrm{Fe}^{2+}$ preferably occupies the $M 11$ octahedra $\left(0.86 \mathrm{Fe}^{2+}\right.$ $\left.+0.14 \mathrm{Fe}^{3+}\right)$, whereas the $\mathrm{Fe}^{3+}$ ions occupy mostly the M12 position $\left(0.14 \mathrm{Fe}^{2+}+0.86 \mathrm{Fe}^{3+}\right)$ (Table 3$)$. The order parameter for the Seriphos ilvaite is the same (within $1 \sigma$ ) as the values of Q reported by Carrozzini (1994) and Ghose et al. (1984), 0.58 and 0.69, respectively, but it is larger than the value given by Finger \& Hazen (1987), 0.16.

The order parameter for manganilvaite $\mathrm{Q}=0.65(10)$, determined from the combined X-ray and neutron powder-diffraction refinements, shows that substitution of $\mathrm{Mn}^{2+}$ at the $M 2$ site slightly increases the $\mathrm{Fe}^{2+}-\mathrm{Fe}^{3+}$ disorder at the $M 11$ and $M 12$ sites (Table 3). The order parameter determined from the X-ray single-crystal refinement is even smaller, $Q=0.26(12)$, which correlates with the difference in the $\beta$ angle (Table 1) and suggests that there may be variation of the order parameter in different crystals from the same deposit.

\section{Mössbauer study}

Ilvaite has been the subject of numerous ${ }^{57} \mathrm{Fe}$ Mössbauer studies (Herzenberg \& Riley 1969, Gérard \& Grandjean 1971, Grandjean \& Gérard 1975, Heilmann et al. 1977, Nolet \& Burns 1979, Amthauer \& Evans 1978, Yamanaka \& Takéuchi 1979, Evans \& Amthauer 1980, Litterst \& Amthauer 1984, Demelo et al. 1994, Cesena et al. 1995, Amthauer et al. 1998, Dotson \& Evans 1999). It has been shown that the monoclinic-orthorhombic transition in ilvaite is accompanied by temperature-activated delocalization of electrons (Ghazi-Bayat et al. 1989, Güttler et al. 1989). The degree of electron delocalization at room temperature can be related to the paragenesis of the mineral (Nolet \& Burns 1979).

Following Nolet \& Burns (1979) and Amthauer \& Rossman (1984), the Mössbauer spectra of the Seriphos ilvaite and of manganilvaite (Fig. 5) were fitted to five quadruple doublets: two corresponding to $\mathrm{Fe}^{2+}$ and mixed-valence $\mathrm{Fe}^{2.5+}$ ions at the $M 11$ position, two for $\mathrm{Fe}^{3+}$ and $\mathrm{Fe}^{2.5+}$ ions at the $M 12$ position, and one doublet 

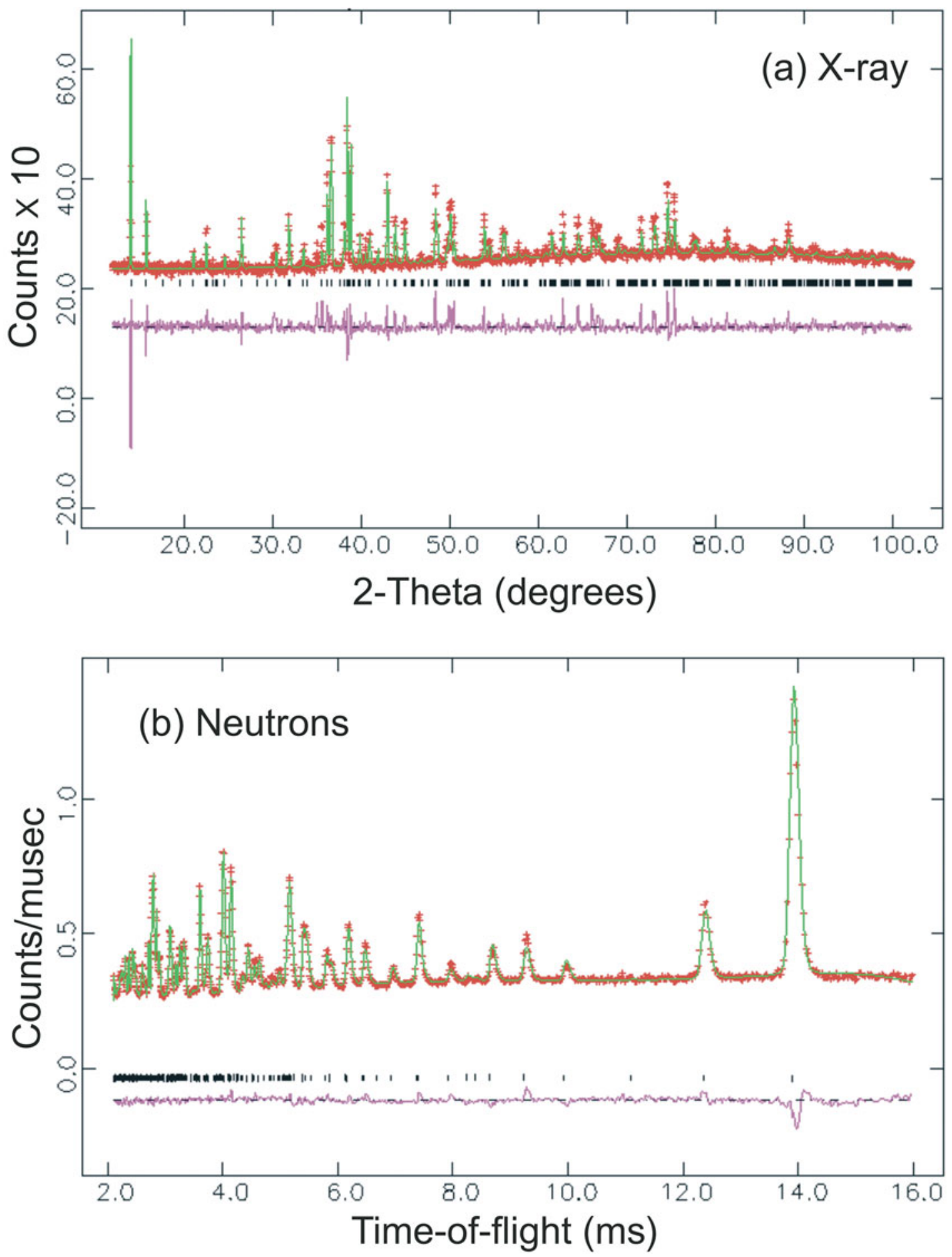

FIG. 3. (a) X-ray and (b) neutron powder-diffraction patterns for manganilvaite (crosses). Also shown are results of the Rietveldfitted calculated profiles (solid lines, top) and the residual (bottom). 
for the $\mathrm{Fe}^{2+}$ ions at the $M 2$ position. The low degree of occupancy of $M 11$ and $M 12$ by $\mathrm{Fe}^{3+}$ and $\mathrm{Fe}^{2+}$, respectively, makes a seven-doublet model less probable.

The interpretation of the Mössbauer spectrum of manganilvaite shows better agreement between the experimental and fitted spectra if electron-exchange interactions $\left(\mathrm{Fe}^{2.5+}\right.$ species) are considered. This model is also supported by the results obtained from the X-rayand neutron-diffraction refinements. The interatomic distances between $\mathrm{Fe}$ ions in adjacent $M 11$ and $M 12$ octahedra along the chains in the manganilvaite structure [2.841(1) and 2.999(1) $\AA$ ] are close to the optimal values and within the $3 \AA$ limit (Swinnea \& Steinfink 1983) necessary for $3 d^{6} \mathrm{Fe}^{2+} \leftrightarrow 3 d^{5} \mathrm{Fe}^{3+}$ electron exchange. The potential for experimental determination of the mixed valence state by Mössbauer spectroscopy depends on the $T_{L} / T_{E}$ ratio, where $T_{L}$ is the Larmor precession time of the $14.4 \mathrm{keV}$ excited state and $\mathrm{T}_{\mathrm{E}}$ is

TABLE 4. BOND LENGTHS (A) FOR ILVAITE AND MANGANILVAITE

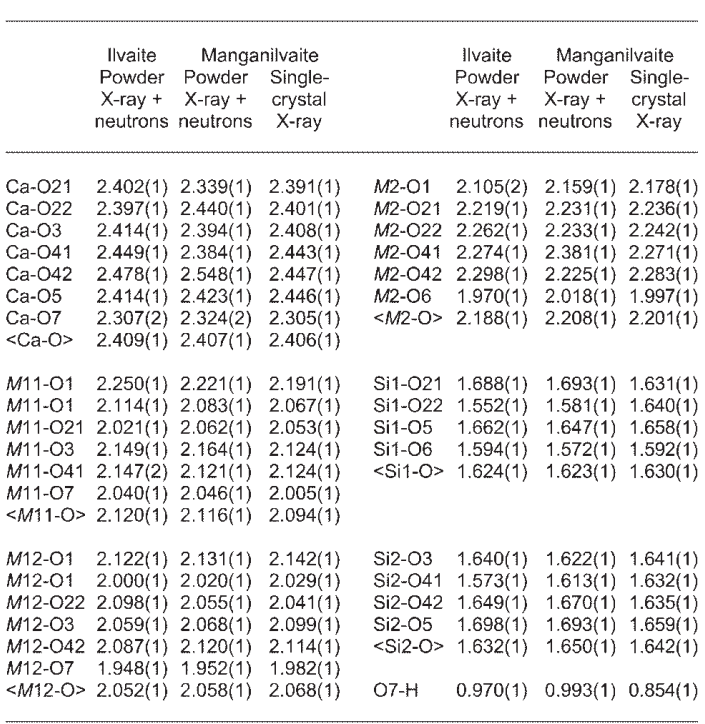

TABLE 5. AVERAGE BOND-LENGTH $\angle \Delta \mid>(\AA)$ AND OM-O BOND ANGLE $\left\langle\Delta T>\left({ }^{\circ}\right)\right.$ OCTAHEDRON DISTORTIONS

\begin{tabular}{lllll}
\hline Site & $\begin{array}{c}\text { Distortion } \\
\text { index }\end{array}$ & $\begin{array}{c}\text { Ilvaite, Seriphos } \\
\text { X-ray }+ \\
\text { neutrons }\end{array}$ & $\begin{array}{c}\text { Manganilvaite, Ossikovo } \\
\text { X-ray }+ \\
\text { neutrons }\end{array}$ & $\begin{array}{c}\text { single- } \\
\text { crystal X-ray }\end{array}$ \\
\hline \multirow{3}{*}{$M 11$} & $\langle\Delta\rangle^{*}$ & 0.08 & 0.06 & 0.06 \\
$M 12$ & $\langle\Delta\rangle^{8}$ & 4.8 & 4.6 & 4.0 \\
$M 2$ & $\langle\Delta|>$ & 0.07 & 0.06 & 0.06 \\
& $\langle\Delta T\rangle$ & 4.9 & 4.1 & 4.1 \\
& $\langle\Delta|>$ & 0.12 & 0.12 & 0.10 \\
& $\langle\Delta T\rangle$ & 7.2 & 7.7 & 7.9
\end{tabular}

*Average bond-length distortion $\langle\Delta|>=\left[11_{6} \Sigma\left(d_{M-0}-\left\langle d_{M-0}>\right)^{2}\right]^{1 / 3}\right.$; estimated standard errors in $\langle\Delta \mid\rangle^{*}= \pm 0.01 \AA$.

${ }^{2}$ Average bond-angle distortion $\langle\Delta \mathrm{T}\rangle=\left[1 / 12 \Sigma\left(T_{O M O}-\left\langle\mathrm{T}_{\mathrm{ONO}}\right\rangle^{2}\right]^{1 / 2}\right.$; estimated standard errors in $\langle\Delta T\rangle= \pm 0.02^{\circ}$ the electron-relaxation time. If the frequency of electron delocalization is higher than $10^{-7} \mathrm{~s}^{-1}$, then the mixedvalence state could be registered in the Mössbauer spectrum with parameters between those characteristic for $\mathrm{Fe}^{3+}$ and $\mathrm{Fe}^{2+}$.

The Mössbauer spectra are shown in Figure 5 and the corresponding parameters [isomer shifts (IS), quadrupole splittings (QS) and full widths at half maximum (FWHM)] are listed in Table 6. Doublet 1 exhibits a small isomer shift typical for $\mathrm{Fe}^{3+}$ in octahedral coordination (Nolet \& Burns 1979, Hawthorne 1988) and can be assigned to $\mathrm{Fe}^{3+}$ at the $M 12$ site, taking into account the occupancies of the $M 12$ site in manganilvaite and the Seriphos ilvaite (Table 3). Doublets 4 and 5 have IS and QS parameters characteristic of high-spin $\mathrm{Fe}^{2+}$ (Nolet \& Burns 1979, Hawthorne 1988). Doublets 2 and 3 have IS parameters intermediate with respect to $\mathrm{Fe}^{3+}$ and $\mathrm{Fe}^{2+}$, i.e., they can be assigned to the mixedvalence $\mathrm{Fe}^{2.5+}$ species. The bond-length and bond-angle distortions of the $M 2$ octahedra are almost $50 \%$ larger than for the $M 11$ octahedra in both the structures of manganilvaite and the Seriphos ilvaite (Table 5). Using empirical relations between the degree of polyhedron distortions and the quadrupole splitting in silicate minerals (Hawthorne 1988), we can easily assign doublet 5 to the $M 2$ site and doublet 4 to the $M 11$ site. In the Seriphos sample, the bond-length distortion of the $M 11$ octahedron is larger than that of the M12 octahedron, whereas their bond-angle distortions are practically the same. Thus we tentatively assign doublets 2 and 3 in both samples to the $\mathrm{Fe}^{2.5+}$ species at the $M 12$ and $M 11$ sites, respectively. The differences in QS parameters for the Seriphos ilvaite and manganilvaite correlate with the corresponding changes in their bondlength distortions (especially for the M11 site).

The contribution of mixed-valence ions in the Seriphos spectrum, measured at room temperature, is insignificant (almost within the error limits). Thus the $M 1$ :

TABLE 6. MÖSSBAUER PARAMETERS FOR ILVAITE AND MANGANILVAITE

\begin{tabular}{|c|c|c|c|c|c|c|}
\hline Doublet & Assigr & nment & IS & QS & FWHM & $G(\%)$ \\
\hline \multicolumn{7}{|c|}{ Ilvaite, Seriphos } \\
\hline 1 & $\mathrm{Fe}^{3+}$ & (M12) & 0.57 & 1.11 & 0.30 & 31.7 \\
\hline 2 & $\mathrm{Fe}^{2.5+}$ & (M12) & 0.62 & 1.40 & 0.30 & 1.7 \\
\hline 3 & $\mathrm{Fe}^{2.5+}$ & (M11) & 0.62 & 1.90 & 0.30 & 1.7 \\
\hline 4 & $\mathrm{Fe}^{2+}$ & (M11) & 0.95 & 2.18 & 0.39 & 31.7 \\
\hline 5 & $\mathrm{Fe}^{2+}$ & $(M 2)$ & 1.01 & 2.43 & 0.30 & 33.2 \\
\hline \multicolumn{7}{|c|}{ Manganilvaite, Ossikovo } \\
\hline 1 & $\mathrm{Fe}^{3+}$ & (M12) & 0.55 & 1.25 & 0.32 & 28.6 \\
\hline 2 & $\mathrm{Fe}^{2.5 t}$ & (M12) & 0.65 & 1.43 & 0.32 & 14.3 \\
\hline 3 & $\mathrm{Fe}^{2.5+}$ & (M11) & 0.65 & 1.99 & 0.40 & 14.3 \\
\hline 4 & $\mathrm{Fe}^{2+}$ & (M11) & 0.92 & 2.10 & 0.42 & 28.6 \\
\hline 5 & $\mathrm{Fe}^{2+}$ & $(M 2)$ & 1.08 & 2.33 & 0.32 & 14.2 \\
\hline
\end{tabular}

Mössbauer parameters for model with five doublets: IS: isomer shift, QS: quadruple splitting, FWHM: full width at half maximum, and G: relative weight of the partial $\mathrm{Fe}$ $\mathrm{components}$ of the spectra. The standard devit
$\mathrm{mm} / \mathrm{s}$, the standard deviations in $\mathrm{G}$ are 0.8 . 


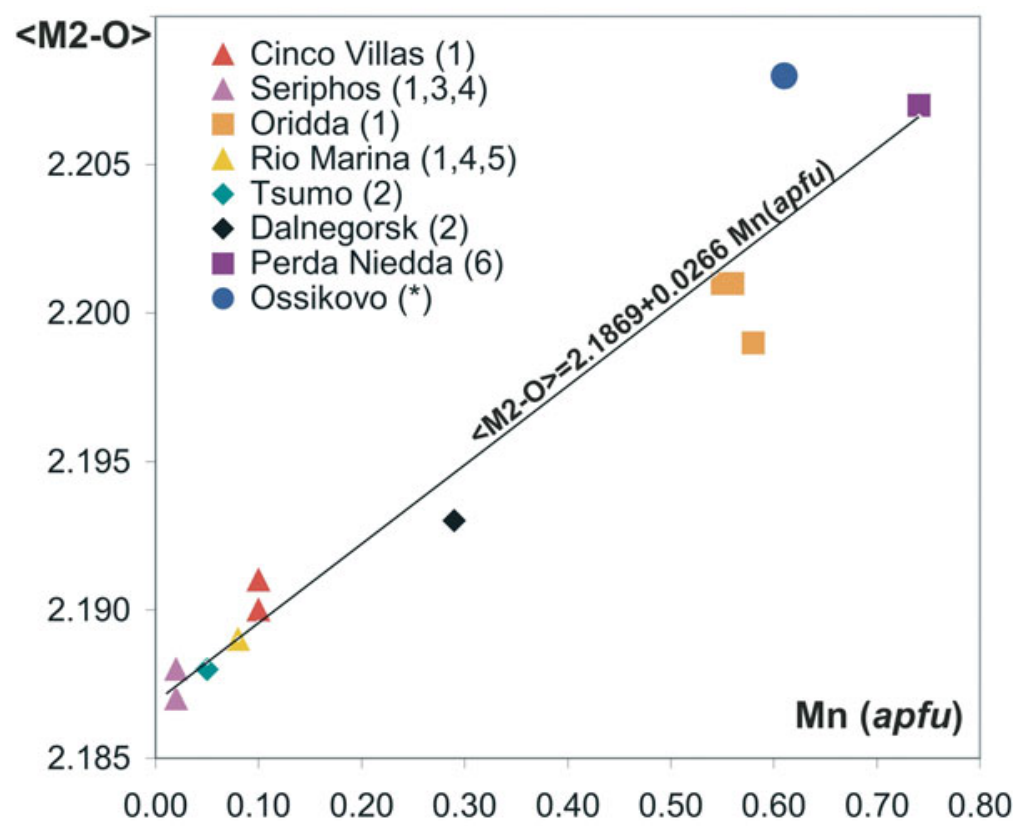

FIG. 4. Variation of $\langle M 2-\mathrm{O}\rangle$ with $\mathrm{Mn}$ content (in $a p f u$ ) in ilvaite-manganilvaite. Data from: (1) Carrozzini (1994), (2) Takéuchi et al. (1983), (3) Finger \& Hazen (1987), (4) Ghose et al. (1984), (5) Bonazzi \& Bindi (1999), (6) Bonazzi \& Bindi (2002), and the present study $(*)$. The line representing the empirical linear equation $\langle M 2-\mathrm{O}\rangle=$ $2.1869+0.0266(9) \mathrm{Mn}^{2+}(a p f u)$ is the one proposed by Carrozzini (1994) and Bonazzi \& Bindi (2002).

$M 2 \mathrm{G}$ ratio is $\sim 2: 1$, as expected from the stoichiometry. The distribution of the Fe ions over the $M 1$ (= M11 + $M 12$ ) and $M 2$ sites in manganilvaite is practically the same (the $\mathrm{G}$ values of the components are normalized to $100 \%$ not considering the $\mathrm{Mn}^{2+}$ ions occupying $M 2$ ). However, the presence of $\mathrm{Mn}^{2+}$ in the ilvaite structure leads to a significant increase in the mixed-valence contribution. The replacement of $\mathrm{Fe}^{2+}$ by $\mathrm{Mn}^{2+}$ at the $M 2$ site results in complex deformations of the $M 11$ and M12 octahedra (Table 5) as well as some changes in the M11-M12 distances. There are two different M11M12 distances along the double chains of octahedra: $M 11-M 12$ and $M 12-M 11^{\prime}$. In the Seriphos ilvaite, $M 11-M 12=3.004(1) \AA$ and $M 12-M 11^{\prime}=2.854(1) \AA$. The distance $M 12-M 11^{\prime}$ remains practically the same $[2.855(1) \AA]$ in manganilvaite, whereas the $M 11-M 12$ distance decreases slightly [2.994(1) $\AA$ ], providing more favorable conditions for electron transfer between these ions. Mössbauer studies on synthetic ilvaite of low Mn content $(<0.19$ apfu) also suggest that incorporation of $\mathrm{Mn}^{2+}$ enhances the valence fluctuations in ilvaite (Ghazi-Bayat et al. 1992, Amthauer et al. 1998).

\section{CONCLUSIONS}

1) The present structural studies confirm that manganilvaite, the new Mn-dominant end-member of the ilvaite group, has the monoclinic ilvaite-type structure.

2) Compositional variations in the ilvaitemanganilvaite series are common among samples from the same deposit and even within a single crystal.

3) In manganilvaite, $\mathrm{Mn}^{2+}$ occurs at the $M 2$ and $\mathrm{Ca}$ sites. The small charge deficit at the $\mathrm{Ca}^{2+}$ site, usually existing in Mn-bearing samples, is the result of partial replacement by $\mathrm{Mn}$, whereas the majority of $\mathrm{Mn}^{2+}$ substitutes for $\mathrm{Fe}^{2+}$ at the $M 2$ site.

4) Replacement of $\mathrm{Fe}^{2+}$ by $\mathrm{Mn}^{2+}$ at the $M 2$ sites leads to an increase in bond-angle distortion of the $M 2$ octahedron, increase of the $\mathrm{Fe}^{2+}-\mathrm{Fe}^{3+}$ disorder, and to an increase in $\mathrm{Fe}^{2+} \leftrightarrow \mathrm{Fe}^{3+}$ charge transfer between the $M 11$ and $M 12$ sites. 


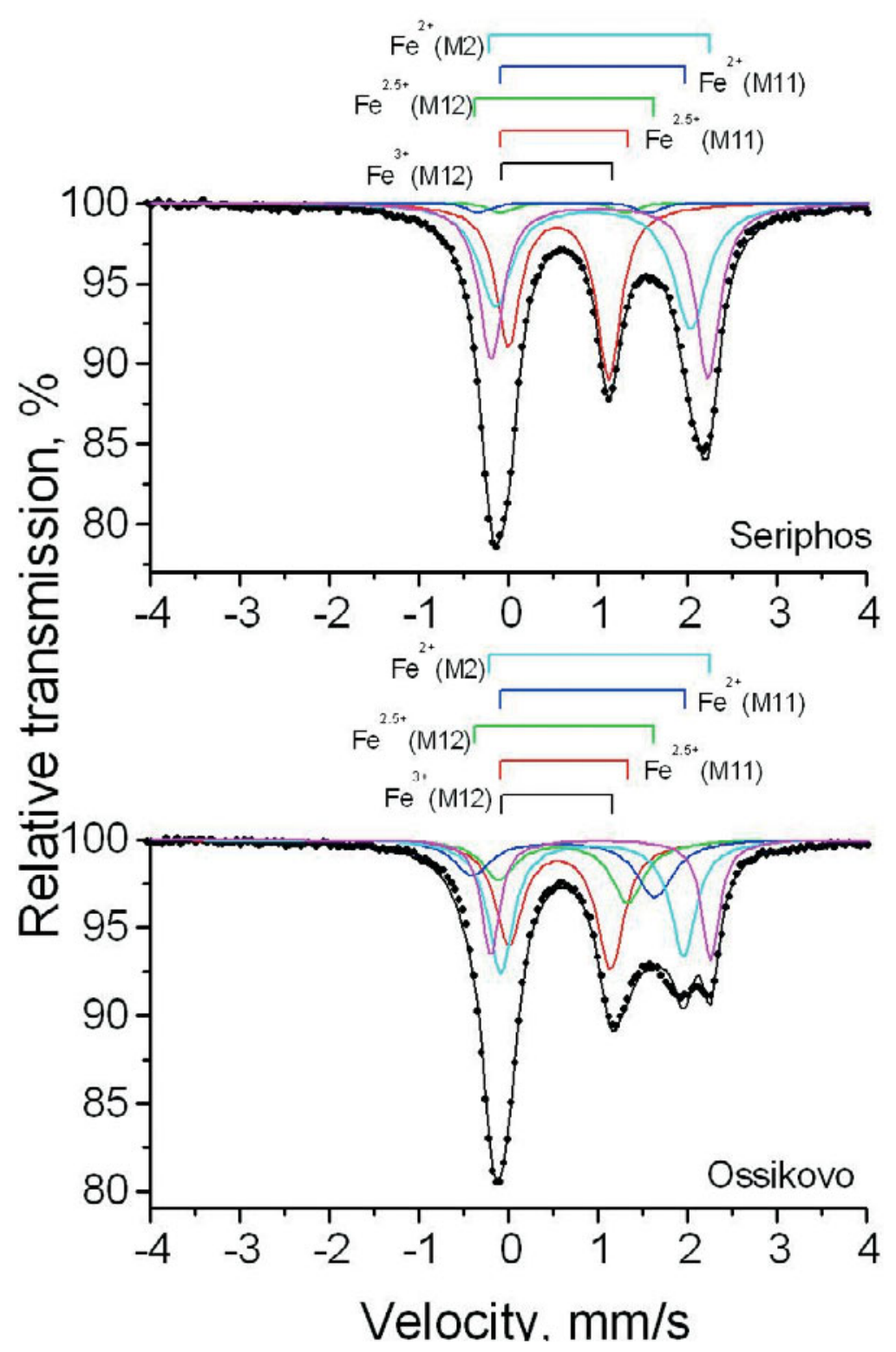

FIG. 5. Mössbauer spectra for Mn-free ilvaite from Seriphos and manganilvaite from Ossikovo.

\section{ACKNOWLEDGEMENTS}

Nikolay Zotov thanks the Bayerisches Geoinstitut (Bayreuth) and SFB 408 (Bonn) for financial support during the preparation of the manuscript. Steven D. Jacobsen thanks J.R. Smyth for diffractometer time at
CU-Boulder and is supported by a Carnegie fellowship, the NSF and the Carnegie/DOE Alliance Center. The authors are also grateful to Paola Bonazzi and Frank C. Hawthorne for the critical and helpful reviews of the manuscript. 


\section{REFERENCES}

Amthauer, G. \& Evans, B.J. (1978): Single crystal and high pressure ${ }^{57} \mathrm{Fe}$ Mössbauer studies of ilvaite $\mathrm{Ca}$ $\mathrm{Fe}_{2}{ }^{2+} \mathrm{Fe}^{3+}\left(\mathrm{Si}_{2} \mathrm{O}_{7} / \mathrm{O} / \mathrm{OH}\right)$ at $298 \mathrm{~K}$. Phys. Chem. Minerals 3, 55-56.

, Lottermoser, W., Redhammer, G. \& TipPelt, G. (1998): Mössbauer studies of selected synthetic silicates. Hyperfine Interactions 113, 219-248.

\& Rossman, G.R. (1984): Mixed valence of iron in minerals with cation clusters. Phys. Chem. Minerals 11, 37-51.

Bartholomé, P., Duchesne, J.C. \& VAn der Plas, L. (1968): Sur une forme monoclinique de l'ilvaite. Ann. Soc. Géol. Belgique 90, 779-788.

Belov, N.V. \& MoKeEvA, V.I. (1954): The crystal structure of ilvaite. Trudy Inst. Kristallogr. Akad. Nauk SSSR 9, 89-102 (in Russ.)

Beran, A. \& Bittner, H. (1974): Untersuchungen zur Kristallchemie des Ilvaits. Tschermaks Mineral. Petrogr. Mitt. 21, 11-29.

BonAZZI, P. \& BINDI, L. (1999): Structural adjustments induced by heat treatment in ilvaite. Am. Mineral. 84, 1604-1612.

$\&$ (2002): Structural properties and heatinduced oxidation-dehydrogenation of manganoan ilvaite from Perda Niedda mine, Sardinia, Italy. Am. Mineral. 87, $845-852$

Bonev, I.K., Vassileva, R.D., Zotov, N. \& Kouzmanov, K. (2005): Manganilvaite, $\mathrm{CaFe}^{2+} \mathrm{Fe}^{3+}\left(\mathrm{Mn}, \mathrm{Fe}^{2+}\right)\left(\mathrm{Si}_{2} \mathrm{O}_{7}\right)$ $\mathrm{O}(\mathrm{OH})$, a new mineral in the ilvaite group, from $\mathrm{Pb}-\mathrm{Zn}$ skarn deposits in the Rhodope Mountains, Bulgaria. Can. Mineral. 43, 1027-1042.

CARROZZINI, B. (1994): Crystal structure refinements of ilvaite: new relationships between chemical composition and crystallographic parameters. Eur. J. Mineral. 6, 465-479.

Cesena, M., Schepke, M., Demelo, M.A.C., Litterst, F.J. \& AmthaueR, G. (1995): Mössbauer studies of Mn- and Al-doped synthetic ilvaites. J. Magnetism and Magnetic Materials 140, 1889-1890.

Cocco, G. \& GaravelLi, C.L. (1954): Studio di alcuni problemi geochimici al giacimento di ferro di Capo Calamita (Elba). Rend. Soc. Ital. Mineral. Petrogr. 10, 269-350.

Demelo, M.A.C., Klauss, H.H., Litterst, F.J. \& Amthauer, G. (1994): Mu+SR and Mössbauer studies of low-dimensional magnetic-ordering in ilvaite. Hyperfine Interactions $85,145-150$.

Dotson, C.R. \& Evans, B.J. (1999): The effects of chemical composition on electron delocalization and magnetic ordering in ilvaite, $\mathrm{Ca}\left[\mathrm{Fe}^{2+}, \mathrm{Fe}^{3+}\right]\left[\mathrm{Fe}^{2+}\right] \mathrm{Si}_{2} \mathrm{O}_{7} \mathrm{O}(\mathrm{OH}) . J$. Appl. Phys. 85, 5234-5236.
Evans, B.J. \& AmthaUER, G. (1980): The electronic structure of ilvaite and the pressure and temperature dependence of its ${ }^{57} \mathrm{Fe}$ Mössbauer spectrum. J. Phys. Chem. Solids 41, 985-1001.

FingeR, L.W. \& HAZEN, R.M. (1987): Crystal structure of monoclinic ilvaite and the nature of the monoclinic-orthorhombic transition at high pressure. Z. Kristallogr. 179, 415-430.

\& Hughes, J.M. (1982): Crystal structure of monoclinic ilvaite. Carnegie Inst. Washington Yearb. 81, 386-388.

FinNEY, J.L. (1995): The complementary use of X-ray and neutron diffraction in the study of crystals. Acta Crystal$\log r$. B51, 447-467.

GÉRARD, A. \& Grandjean, F. (1971): Observation by Mössbauer effect of an electron hopping process in ilvaite. Solid State Commun. 9, 1845-1849.

Ghazi-Bayat, B., Amthauer, G. \& Hellner, E. (1989): Synthesis and characterization of Mn-bearing ilvaite $\mathrm{CaFe}^{2+}{ }_{2-x} \mathrm{Mn}_{x} \mathrm{Fe}^{3+}\left[\mathrm{Si}_{2} \mathrm{O}_{7} / \mathrm{O} /(\mathrm{OH})\right]$. Mineral. Petrol. 40, 101-109.

BehruZi, M., LitTerst, F.J., LotTermoser, W. \& AmthaueR, G. (1992): Crystallographic phase transition and valence fluctuation in synthetic Mn-bearing ilvaite $\mathrm{CaFe}^{2+}{ }_{2-x} \mathrm{Mn}^{2+}{ }_{x} \mathrm{Fe}^{3+}\left[\mathrm{Si}_{2} \mathrm{O}_{7} / \mathrm{O} /(\mathrm{OH})\right]$. Phys. Chem. Minerals 18, 491-496.

Ghose, S., Hewat, A.W. \& Marezio, M. (1984): A neutron powder diffraction study of the crystal and magnetic structures of ilvaite from $305 \mathrm{~K}$ to $5 \mathrm{~K}$ - a mixed valence iron silicate with an electronic transition. Phys. Chem. Minerals 11, 67-74.

, Sen Gupta, P.K. \& Schlemper, E.O. (1985): Electron ordering in ilvaite, a mixed-valence iron silicate: crystal structure refinement at $138 \mathrm{~K}$. Am. Mineral. 70, $1248-1252$

, Tsukimura, K. \& Hatch, D.M. (1989): Phase transitions in ilvaite, a mixed-valence iron silicate. II. A single crystal X-ray diffraction study and Landau theory of the monoclinic to orthorhombic phase transition induced by charge delocalization. Phys. Chem. Minerals 16, 483496.

Grandjean, F. \& GÉRARD A. (1975): Analysis by Mössbauer spectroscopy of the electronic hopping process in ilvaite. Solid State Commun. 16, 553-556.

Güttler, B., Salde, E. \& Ghose, S. (1989): Polarized single crystal absorption spectroscopy of the Pnam-P2 $/ a$ transition of ilvaite $\mathrm{Ca}\left(\mathrm{Fe}^{2+}, \mathrm{Fe}^{3+}\right) \mathrm{Fe}^{2+} \mathrm{Si}_{2} \mathrm{O}_{8}(\mathrm{OH})$, as measured between $300 \mathrm{~K}$ and $450 \mathrm{~K}$. Phys. Chem. Minerals 16, 606-613

HAGA, N. \& TAKÉUCHI, Y. (1976): A neutron diffraction study of ilvaite. Z. Kristallogr. 144, 161-174. 
Hawthorne, F.C. (1988): Mössbauer spectroscopy. In Spectroscopic Methods in Mineralogy and Geology (F.C. Hawthorne, ed.). Rev. Mineral. 18, 255-333.

Heilmann, I.U., Olsen, N.B \& Olsen J.S. (1977): Electron hopping and temperature dependent oxidation states of iron in ilvaite studied by Mössbauer effect. Phys. Scripta 15, 285-288

HerzenberG, C.L. \& Riley, D.L. (1969): Oxidation state and site symmetries of iron in ilvaite using Mössbauer spectrometry. Acta Crystallogr. A25, 389-391.

LARSEN, A.O. \& DAHLGREN, S. (2002): Ilvaite from the Oslo Graben, Norway. Neues Jahrb. Mineral., Monatsh., 169181.

Larson, A.C. \& Von Dreele, R.B. (1987): GSAS - general structure analysis system. Los Alamos Nat. Lab. Rep. LA-UR-86-748.

LitTerst, F.J. \& Amthauer, G. (1984): Electron delocalization in ilvaite, a reinterpretation of its ${ }^{57} \mathrm{Fe}$ Mössbauer spectrum. Phys. Chem. Minerals 10, 250-255.

Nolet, D.A. \& BuRns, R.G. (1979): Ilvaite: a study of temperature dependent electron delocalization by the Mössbauer effect. Phys. Chem. Minerals 4, 221-234.

ShANNON, R.D. (1976): Revised effective ionic radii and systematic studies of interatomic distances in halides and chalcogenides. Acta Crystallogr. A32, 751-767.
Sheldrick, G.M. (1997): SHELXL-97, A Program for Crystal Structure Refinement. Univ. Göttingen, Göttingen, Germany (Release 97-2).

SwinneA, J.S. \& STEINFInK, H. (1983): Crystal structure and Mössbauer spectrum of vonsenite, $2 \mathrm{FeO} \cdot \mathrm{FeBO}_{3} . \mathrm{Am}$. Mineral. 68, 827-832.

Takéuchi, Y., HagA, N. \& Bunno, M. (1983): X-ray study on polymorphism of ilvaite, $\mathrm{HCaFe}^{2+}{ }_{2} \mathrm{Fe}^{3+} \mathrm{O}_{2}\left[\mathrm{Si}_{2} \mathrm{O}_{7}\right]$. $Z$. Kristallogr. 163, 267-283.

SAWAdA, H. \& TANIGUChI, H. (1993): The ilvaite problem. Proc. Inst. Natural Sci., Nihon Univ. 28, 39-43.

UNO, R. \& TABIRA, Y. (1994): Submicroscopic twinning and chemical inhomogeneity of ilvaite, a mixed-valence iron sorosilicate $\mathrm{HCaFe}^{2+}{ }_{2} \mathrm{Fe}^{3+} \mathrm{Si}_{2} \mathrm{O}_{9}$. Z. Kristallogr. 209, 861-869.

YAMANAKA, T. \& TAKÉUCHI, Y. (1979): Mössbauer spectra and magnetic features of ilvaites. Phys. Chem. Minerals 4, 149-159.

Received May 18, 2004, revised manuscript accepted March 10, 2005. 